Vries, A.H. de, Lesterhuis, E., Verweij, L.M., Schout, B.M.A., Horst, H.J.R. van der, Leppink, J., Koldewijn, E.L., Wagner, C. High level of patient satisfaction and comfort during diagnostic urological procedures performed by urologists and residents. Scandinavian Journal of Urełogy:7 2016, 50(3), 206-211

\begin{tabular}{|l|l|}
\hline $\begin{array}{l}\text { Postprint } \\
\text { Version }\end{array}$ & 1.0 \\
\hline Journal website & $\frac{\text { http://www.tandfonline.com/doi/full/10.3109/21681805.2015.1116109\#.V6BkdE1f }}{\underline{1 \mathrm{Mw}}}$ \\
\hline Pubmed link & $\underline{\text { http://www.ncbi.nlm.nih.gov/pubmed/26635064 }}$ \\
\hline DOI & $10.3109 / 21681805.2015 .1116109$
\end{tabular}

This is a NIVEL certified Post Print, more info at http://www.nivel.eu

\title{
High level of patient satisfaction and comfort during diagnostic urological procedures performed by urologists and residents
}

\author{
H. DE VRIES, E. Lesterhuis, L. M. VerweiJ, B. M. A. SChOUt, H. J. R. VAN DER Horst, J. \\ LEPPINK, E. L. KOLDEWIJN \& C. WAGNER
}

\begin{abstract}
Objective. The aim of this study was to investigate how patients experience diagnostic urological procedures performed by urologists, junior residents and senior residents, and to assess the influence of procedure-related factors on patient experiences. Methods. Data were collected during 222 procedures: 84 transrectal ultrasound-guided prostate biopsies (TRUSP; urologists $\mathrm{n}=39$, residents $n=45$ ) and 138 urethrocystoscopies (UCS; urologists $n=44$, residents $n=94$ ) in six hospitals. Patient experiences were assessed using a questionnaire focusing on pain, comfort and satisfaction (visual analogue scale, 0-10) and communication aspects on a four-point Likert scale. Clinical observations were made to identify influencing factors. Results. Median values for patient experiences across procedures were 10 (range 5-10) for patient satisfaction, $2(0-9)$ for pain and $8(0-10)$ for comfort. Generalized estimating equations revealed no significant differences between urologists, senior residents and junior residents in terms of experienced patient comfort, satisfaction or pain. Procedural time was longer for residents, but this did not correlate significantly with patient-experienced comfort $(\mathrm{p}=0.3)$. In UCS, patient comfort and satisfaction were higher in the supine position for male and female patients, respectively ( $<<0.01)$. In TRUSP, local anaesthesia resulted in a significant decrease in pain $(\mathrm{p}=0.002)$ and an increase in comfort $(\mathrm{p}=0.03)$. Finally, older patients experienced less pain and gave higher comfort and satisfaction responses than younger patients. Conclusions. Patients expressed high levels of satisfaction and comfort during diagnostic urological procedures. Experiences were not affected by the level of training, suggesting highly developed interpersonal and communication skills for residents in an early stage of residency training. Patients demonstrated significant preferences for local anaesthesia in TRUSP and performance of UCS in the supine position over the lithotomy position.
\end{abstract}


Vries, A.H. de, Lesterhuis, E., Verweij, L.M., Schout, B.M.A., Horst, H.J.R. van der, Leppink, J., Koldewijn, E.L., Wagner, C. High level of patient satisfaction and comfort during diagnostic urological procedures performed by urologists and residents. Scandinavian Journal of Urełogy:7 2016, 50(3), 206-211

\section{INTRODUCTION}

In urology, the transrectal ultrasound-guided prostate biopsy (TRUSP) and urethrocystoscopy (UCS) are essential basic diagnostic procedures. These procedures are routinely performed in the outpatient department by urologists and residents. In the Netherlands, residents train their practical skills in a patient-related setting. Prior to their traineeship, all residents participate in a 2 day practical course, in which they receive training in basic urological skills (including UCS and TRUSP) in a nonpatient-related setting on simulation models. Faculty supervision is a routine part of resident training and practice, and there is continuous supervision for all the procedures performed in the operating room. However, for procedures performed in the outpatient department, supervision is available upon request but most of the time is not continuously present.

Several factors are known to influence patient comfort and experienced pain during UCS and TRUSP, such as the type of cystoscope in UCS

[1Greenstein A, GreensteinI, Senderovich S,Mabjeesh NJ. Is diagnostic cystoscopy painful? Analysis of 1,320 consecutive procedures.Int Braz J Urol2014;40:533-8.]. For both procedures, adequate training has the potential to optimize patient comfort and diagnostic accuracy [2Nguyen CT, Gao T,Hernandez AV, Jones JS.Can residents perform transrectal ultrasound-guided prostate biopsy with patient comfort comparable to biopsy performed by attending staff urologists? Prostate Cancer Prostatic Dis2010;13:52-7.,3Nguyen CT, Babineau DC,Jones JS. Impact of urologic resident training on patient pain and morbidity associated with office-based cystoscopy.Urology 2008;71:782-6.]. Furthermore, non-technical aspects, such as communication, can influence patient satisfaction during endoscopic procedures [4Qureshi MO, Shafqat F,Ahmed S, Niazi TK,Khokhar N. Factors affecting patient satisfaction during endoscopic procedures. J Coll Physicians Surg Pak2013;23:7759.]. However, little is known about the acquisition of this non-technical skill during residency, or about the impact of resident training and the presence of a supervisor on patient experiences and patient satisfaction.

This study aimed to investigate these issues by addressing the research questions: "How do patients experience diagnostic urological procedures performed by urologists, junior and senior residents?" and "What is the influence of procedurerelated factors on patient experiences?"

\section{MATERIALS AND METHODS}

Data were collected during TRUSP and UCS performed by urologists and residents in six teaching hospitals across the Netherlands. For practical reasons, patients were included during three periods between November 2012 and October 2014. Within these periods, the aim was to include all patients who were scheduled for TRUSP or UCS in the particular hospitals. This was not always possible because of simultaneous consulting hours of urologists and residents. A description of the exact inclusion periods and the corresponding numbers of patients is shown in a flowchart (see Appendix I in the supplementary material).

The urological residency programme consists of a 4 year traineeship. Residents until their second year of urological training were categorized as "junior residents". Residents in their third and fourth years of training were categorized as "senior residents". 
Vries, A.H. de, Lesterhuis, E., Verweij, L.M., Schout, B.M.A., Horst, H.J.R. van der, Leppink, J., Koldewijn, E.L., Wagner, C. High level of patient satisfaction and comfort during diagnostic urological procedures performed by urologists and residents. Scandinavian Journal of Urełogy:7 2016, 50(3), 206-211

Ethical approval was obtained from the institutions' ethics committees. Written informed consent with the assurance of anonymity and confidentiality was obtained from all patients and professionals before the start of the procedure.

\section{Patient questionnaire}

Patient experiences were assessed using a questionnaire based on the validated Consumer Quality Index (CQI) [5Delnoij DM, RademakersJJ, Groenewegen PP. The Dutch consumer quality index: an example of stakeholder involvement in indicator development.BMC Health Serv Res2010;10:88.]. CQI is a registered trademark, developed as a national standard for measuring patient experiences with healthcare providers and health plans. The questionnaire, adapted and piloted for this specific study, comprised 19 questions divided into three categories. Four questions focused on demographics and patients' previous experiences. Nine questions focused on the provision of information, communication and aftercare, e.g. the possibility to ask questions and the provision of understandable information. Answer options for these questions were graded on a four-point Likert scale (from $1=$ not at all to 4 = completely agree). The last six questions focused on the patient's overall experience, e.g. pain, comfort and overall satisfaction. These questions were rated on a visual analogue scale (VAS; $0-10$ ). Patients were requested to complete the questionnaire in the hospital directly after the procedure or, if this was not possible, to complete it at home and return it to the principal researcher by post or e-mail.

Patients who partially completed the questionnaire or failed to return the questionnaire were excluded from the study. A copy of the questionnaire can be obtained from the primary author upon request.

\section{Clinical observations}

Clinical observations were performed to evaluate procedure-related factors that could influence patient experiences. Detailed scoring lists for TRUSP and UCS were developed and piloted. These scoring lists contained information on the indication of the procedure, the use of analgesics within $24 \mathrm{~h}$ before the procedure, the presence of a supervisor (for residents) and procedural time, defined as "doctor puts gloves on doctor takes gloves off". In all procedures performed by residents, the patientphysician interaction was primarily provided by the resident, including when a supervising urologist was continuously present. For procedures primarily performed by urologists, there were no residents attending.

For TRUSP in particular, records were kept of the patient's position (left lateral/lithotomy), periprostatic lidocaine injection (yes/no) and the number of biopsies that were taken. For UCS, records were kept of the patient's position (supine/lithotomy), the type of cystoscope (rigid/flexible) and the type of lubrication (Endosgel ${ }^{\circledR} /$ Instillagel ${ }^{\circledR}$ ) that was used. Patients who had used opiates within $24 \mathrm{~h}$ before the procedure were excluded from the study. The observations were performed by three observers, who received detailed instructions before the observations to ensure high interobserver reliability.

\section{Data analysis}

The required sample size was calculated a priori, based on earlier studies [2Nguyen CT, Gao T,Hernandez AV, Jones JS.Can residents perform transrectal ultrasound-guided prostate biopsy with patient comfort comparable to biopsy performed by attending staff urologists? Prostate Cancer Prostatic Dis2010;13:527.,3Nguyen CT, Babineau DC,Jones JS. Impact of urologic resident training on 
Vries, A.H. de, Lesterhuis, E., Verweij, L.M., Schout, B.M.A., Horst, H.J.R. van der, Leppink, J., Koldewijn, E.L., Wagner, C. High level of patient satisfaction and comfort during diagnostic urological procedures performed by urologists and residents. Scandinavian Journal of Urełogy:7 2016, 50(3), 206-211

patient pain and morbidity associated with office-based nivel cystoscopy.Urology 2008;71:782-6.]. The minimum clinically relevant difference in pain score between urologists and residents was assumed to be 1.5 points [6Gallagher EJ, Liebman M,Bijur PE. Prospective validation of clinically important changes in pain severity measured on a visual analog scale. Ann Emerg Med2001;38:633-8.]. For TRUSP, using a standard deviation of 2.23, a power of 0.8 and an alpha of 0.05 , the minimum required number of patients per group was 36 . For UCS, using a standard deviation of 1.88 , a power of 0.8 and an alpha of 0.05 , the minimum required number of patients per group was 26 .

To address the aforementioned research questions (an interest in population or fixed effects, not in individuals) while accounting for the structure of the data (mostly multiple cases per resident/urologist, and some departure from normal, homoscedastic residuals), generalized estimating equations (GEE) were used (performed in SPSS version 22.0; SPSS, Chicago, IL, USA), with patient comfort, patient satisfaction and pain experienced by the patient as response variables.

\section{RESULTS}

In total, 240 patients (TRUSP $n=90, \operatorname{UCS} n=150$ ) were included in the data collection of this study. Procedures were performed by nine urologists, 14 junior residents and four senior residents. Sixteen patients were excluded owing to their failure to return the questionnaire or to partial completion of the questionnaire (TRUSP $n=4, \operatorname{UCS} n=12$ ). One TRUSP patient was excluded because of the use of opiates within $24 \mathrm{~h}$ before the procedure, and one patient was excluded because magnetic resonance imaging fusion had been added to the regular TRUSP procedure. This led to the inclusion of 222 patients (TRUSP $n=84$, UCS $n=138$ ) in the final study cohort. Of these, the satisfaction scores of two UCS and two TRUSP patients, and the pain scores of six UCS patients were excluded from further analysis owing to misinterpretation of the questions. The demographics are described in Table 1.

\section{[TABLE 1]}

\section{Patient experiences}

Median values for patient experiences across procedures were 10 (range 5-10) for patient satisfaction, $2(0-9)$ for pain and $8(0-10)$ for patient comfort. Tables $2-$ 4 present the outcomes of GEE on patient experiences across procedures (Table 2), for UCS in male (Table 3a) and female (Table 3b) patients, and for TRUSP (Table 4). As Table 2 indicates, there were no statistically significant differences in patient satisfaction, comfort or pain for procedures performed by urologists, junior or senior residents. Experienced pain was significantly lower during UCS than during TRUSP [2 (0-8) vs $3(0-9), p=0.004]$. Procedural time was longest for junior residents [7 (1-20) $\mathrm{min}$ ] and shortest for urologists [4 (1-12) min, $\mathrm{p}<0.01]$, but this appeared to have no impact on patient experiences. Furthermore, older patients experienced less pain and gave higher comfort and satisfaction responses than younger patients. The effect of patients' previous experiences on the outcome measures is difficult to interpret, as patients with more previous experiences did not always report higher or lower scores on the outcome measures. However, when not including previous experiences in the model, differences between urologists, senior and junior residents on the outcome measures may partly reflect differences between these three groups 
Vries, A.H. de, Lesterhuis, E., Verweij, L.M., Schout, B.M.A., Horst, H.J.R. van der, Leppink, J., Koldewijn, E.L., Wagner, C. High level of patient satisfaction and comfort during diagnostic urological procedures performed by urologists and residents. Scandinavian Journal of Urełogy:7 2016, 50(3), 206-211

in terms of which patients they treated (with some patients having had more nive experiences than others). By including previous experiences in the model, it was possible to statistically control for such confounding.

\section{[TABLE 2]}

\section{[TABLE 3]}

\section{[TABLE 4]}

Patients were highly satisfied with the degree of communication (92\%), provision of information (94\%) and the aftercare $(78 \%)$ provided by their physician.

All UCS procedures in male patients were performed using a flexible scope. Patient comfort was significantly higher in the supine position than in the lithotomy position (Table 3a). The use of intraurethral lidocaine had no impact on experienced pain. For UCS in female patients (Table $3 b$ ), patient satisfaction was significantly higher in the supine position than in the lithotomy position. Again, the use of lidocaine had no impact on experienced pain, but patient satisfaction appeared to be significantly higher in the intraurethral lidocaine group. In TRUSP, after removing the least significant terms from the model reflected in Table 4 - which yields an increased statistical power for the remaining terms in the model - local anaesthesia resulted in a significant decrease in pain $(\mathrm{p}=0.002)$ and a significant increase in comfort $(\mathrm{p}=0.031)$.

\section{DisCussion}

This study investigated how patients experience the diagnostic procedures TRUSP and UCS performed by urologists, junior residents and senior residents. The results showed that patients were equally satisfied with the practical skills and the communication skills of urologists and residents. The level of residency training had no impact on patients' experiences.

To the authors' knowledge, this study is the first to evaluate the influence of residency training on patient satisfaction and comfort during diagnostic urological procedures. Two studies by Nguyen and colleagues have previously addressed the impact of residency training on experienced pain during TRUSP and UCS [2Nguyen CT, Gao T,Hernandez AV, Jones JS.Can residents perform transrectal ultrasound-guided prostate biopsy with patient comfort comparable to biopsy performed by attending staff urologists? Prostate Cancer Prostatic Dis2010;13:527.,3Nguyen CT, Babineau DC,Jones JS. Impact of urologic resident training on patient pain and morbidity associated with office-based cystoscopy.Urology 2008;71:782-6.]. Although their urological curriculum may not be completely comparable, for UCS the results were in accordance with the results presented in the current study, as they found no significant differences in pain scores between procedures performed by residents versus urologists, or between the different training levels [3Nguyen CT, Babineau DC,Jones JS. Impact of urologic resident training on patient pain and morbidity associated with office-based cystoscopy.Urology 2008;71:782-6.]. For TRUSP, however, Nguyen and colleagues found a potential for increased pain in the resident group during probe insertion and obtaining core biopsies in the residents group 
Vries, A.H. de, Lesterhuis, E., Verweij, L.M., Schout, B.M.A., Horst, H.J.R. van der, Leppink, J., Koldewijn, E.L., Wagner, C. High level of patient satisfaction and comfort during diagnostic urological procedures performed by urologists and residents. Scandinavian Journal of Urełogy:7 2016, 50(3), 206-211

[2Nguyen CT, Gao T,Hernandez AV, Jones JS.Can residents perform transrectal ultrasound-guided prostate biopsy with patient comfort comparable to biopsy performed by attending staff urologists? Prostate Cancer Prostatic Dis2010;13:527.]. Still, the clinical relevance was questioned, since the greatest spread of difference in pain scores was only 6 on a $0-100$ scale, and the minimum change in pain that is clinically relevant was shown to be 13 on a $0-100$ VAS [6Gallagher EJ, Liebman M,Bijur PE. Prospective validation of clinically important changes in pain severity measured on a visual analog scale. Ann Emerg Med2001;38:633-8.].

The results of this study indicate that residents' interpersonal and communication skills are already highly developed in an early stage of urological residency training. This competency is one of the six core competencies that residency programmes need to fulfil, according to the requirements of the Accreditation Council for Graduate Medical Education (ACGME) [7Teutsch C. Patient-doctor communication. Med Clin North Am2003;87:1115-45.]. It seems that in the current Dutch curriculum, sufficient attention is drawn to interpersonal and communication skills regarding TRUSP and UCS, and that the focus in skills training should be directed towards other problem areas. High levels of patient comfort and patient satisfaction during TRUSP and UCS do not per se reflect the technical ability of the physician. A recent study showed that residents' performance of basic urological procedures, especially TRUSP, involves a high percentage of unintended events, which are mainly caused by human factors and result in a potential threat to patient safety [8de Vries AH, Boute MC,Kuppen MC, van

Merrienboer JJ, KoldewijnEL, Pelger RC, et al.Patient safety risks of basic urological procedures performed by junior and senior residents. J Surg Educ2015;72:918-26.]. This indicates the need for targeted practical skills training, including assessment, before privileges for independent practice are granted. Procedural time appeared to be longest for junior residents and shortest for urologists. This is in concordance with the process of skills acquisition described by Ericsson, in which clinicians with increasing experience can generate the same outcomes more quickly and more efficiently [9Ericsson KA. Deliberate practice and acquisition of expert performance: a general overview. Acad Emerg

Med2008;15:988-94.]. Fortunately, this longer procedural time appeared to have no impact on patient experiences.

Concerning procedural-related factors that could influence patient experiences of TRUSP, the present study revealed that periprostatic lidocaine injection resulted in decreased pain perception during TRUSP. This finding is in accordance with previous research [10-12Lee C, Woo HH. Current methods of analgesia for transrectal ultrasonography (TRUS)-guided prostate biopsy - a systematic review. BJU Int2014;113(Suppl 2):48-56.<br

> Tufek I, Akpinar H,Atug F, Obek C, Esen HE,Keskin MS, et al. The impact of local anesthetic volume and concentration on pain during prostate biopsy: a prospective randomized trial. J Endourol 2012;26:174-7. $<$ br

> Lynn NN, CollinsGN, Brown SC, O'Reilly PH.Periprostatic nerve block gives better analgesia for prostatic biopsy. BJU Int2002;90:424-6.].

For UCS, procedures performed in the supine position led to significantly higher patient satisfaction in female patients and higher patient comfort in male patients compared to the lithotomy position. These results suggest that professionals should 
Vries, A.H. de, Lesterhuis, E., Verweij, L.M., Schout, B.M.A., Horst, H.J.R. van der, Leppink, J., Koldewijn, E.L., Wagner, C. High level of patient satisfaction and comfort during diagnostic urological procedures performed by urologists and residents. Scandinavian Journal of Urełogy:7 2016, 50(3), 206-211

be encouraged to use the supine position as their standard position. The effect of type of scope on patient experiences was only analysed in the female group, since all male patients underwent UCS with a flexible scope. The results indicate that type of scope had no influence on patient experiences. This is contradictory to previous research, showing that experienced pain was significantly higher for patients undergoing UCS with a rigid scope compared with a flexible scope

[1Greenstein A, GreensteinI, Senderovich S,Mabjeesh NJ. Is diagnostic cystoscopy painful? Analysis of 1,320 consecutive procedures.Int Braz J Urol2014;40:533-8.]. Still, the results of the current study should be interpreted with care, since only 12 women underwent UCS with a rigid scope. This group should be extended before a reliable analysis can be performed and clear conclusions can be drawn. Finally, the use of intraurethral 2\% lidocaine hydrochloride gel (Instillagel) did not result in a reduction of experienced pain in male or female patients. A meta-analysis performed by Patel and colleagues also showed no significant pain reduction when using lidocaine lubrication during flexible cystoscopy in male patients [13Patel AR, Jones JS,Babineau D. Lidocaine 2\% gel versus plain lubricating gel for pain reduction during flexible cystoscopy: a meta-analysis of prospective, randomized, controlled trials. J Urol2008;179:986-90.]. Perhaps the discomfort experienced by patients undergoing UCS is not directly associated with pain, but more with complaints such as a sense of shame or irritation. Taking these results into account, it would be a logical measure to switch to plain lubrication. This could increase delivery comfort and prevent the potential side-effects of intraurethral lidocaine, such as local irritation and hypersensitivity reactions [14Ho KJ, Thompson TJ,O'Brien A, Young MR,McCleane G. Lignocaine gel: does it cause urethral pain rather than prevent it? Eur Urol2003;43:194-6.]. Unfortunately, because of the limited number of female patients receiving UCS with a rigid scope, it was not possible to perform a reliable analysis on the effect of lidocaine in rigid versus flexible UCS in female patients. This could be an interesting topic for future study.

Data collection was performed in six teaching hospitals, to ensure a reliable representation of patient experiences across the country. Practical reasons led to a relatively long total inclusion period. It should be stressed that the three inclusion periods within the total time-frame were limited, ranging from 3 to 8 months, depending on the number of procedures performed in the particular hospital. Compared to a randomized controlled experiment, the practical design of this study resulted in some imbalance between groups in terms of patient-related factors such as previous experiences, and a lack of procedural and equipment standardization for the professionals. However, the advantage of such a design is that it represents the real situation. Moreover, the aforementioned imbalance was accounted for in the statistical analysis of the data acquired in this study.

Unfortunately, no details were known regarding prior experiences of the professionals in the performance of UCS and TRUSP. Consequently, patient experiences could not be statistically linked to the actual number of procedures performed by the professionals. This is why the patient experiences are presented for junior versus senior levels of training. Since exposure and experience increase with training year, the authors think that the results provide an accurate representation of the current situation for the two levels of training. 
Vries, A.H. de, Lesterhuis, E., Verweij, L.M., Schout, B.M.A., Horst, H.J.R. van der, Leppink, J., Koldewijn, E.L., Wagner, C. High level of patient satisfaction and comfort during diagnostic urological procedures performed by urologists and residents. Scandinavian Journal of Urełogy:7 2016, 50(3), 206-211

In this study, some patients were assigned to a particular urologist or resident from the initial visit, whereas others were randomly placed on the programme of a physician whom they had not encountered before. Patients' confidence in a physician could affect their perception of the physician's skills and the ensuing comfort. Patients assigned to a particular physician from the initial visit already know the perceived skill level of the physician and this may have shaped their responses accordingly. This "perception" variable was not specifically accounted for in this study. Consequently, it was not possible to correct for this potentially confounding perception bias. The inclusion of a perception scale of confidence in the urologist performing the procedure prior to the actual procedure could be interesting for future study. Finally, owing to the limited number of cases in which a supervisor was present during UCS and TRUSP performed by residents, it was not possible to estimate the effect of supervision on patient experiences. This would also be an interesting topic of future research.

In conclusion, patients expressed high levels of satisfaction and comfort during diagnostic urological procedures. Experiences were not affected by the level of training (junior resident, senior resident, urologist), suggesting highly developed interpersonal and communication skills for residents in an early stage of residency training. Patients demonstrated significant preferences for local anaesthesia in TRUSP and the performance of UCS in the supine position over the lithotomy position.

\section{Acknowledgements}

The authors gratefully acknowledge Malou Kuppen for her efforts in data collection, Lisette van Hulst for editorial assistance, and all patients, residents and urologists for their participation in this study.

\section{DECLARATION OF INTEREST}

The authors A.H. de Vries, E. Lesterhuis, L.M. Verweij, B.M.A. Schout, H.J.R. van der Horst, J. Leppink, E.L. Koldewijn and C. Wagner declare that they have no conflicts of interest or financial ties to disclose.

\section{REFERENCES}

[1] Greenstein A, Greenstein I, Senderovich S, Mabjeesh NJ. Is diagnostic cystoscopy painful? Analysis of 1,320 consecutive procedures. Int Braz J Urol 2014;40:533-8.

[2] Nguyen CT, Gao T, Hernandez AV, Jones JS. Can residents perform transrectal ultrasound-guided prostate biopsy with patient comfort comparable to biopsy performed by attending staff urologists? Prostate Cancer Prostatic Dis 2010;13:52-7.

[3] Nguyen CT, Babineau DC, Jones JS. Impact of urologic resident training on patient pain and morbidity associated with office-based cystoscopy. Urology 2008;71:782-6.

[4] Qureshi MO, Shafqat F, Ahmed S, Niazi TK, Khokhar N. Factors affecting patient satisfaction during endoscopic procedures. J Coll Physicians Surg Pak 2013;23:775-9.

[5] Delnoij DM, Rademakers JJ, Groenewegen PP. The Dutch consumer quality index: an example of stakeholder involvement in indicator development. BMC Health Serv Res 2010;10:88.

[6] Gallagher EJ, Liebman M, Bijur PE. Prospective validation of clinically important changes in pain severity measured on a visual analog scale. Ann Emerg Med 2001;38:633-8.

[7] Teutsch C. Patient-doctor communication. Med Clin North Am 2003;87:1115-45. 
Vries, A.H. de, Lesterhuis, E., Verweij, L.M., Schout, B.M.A., Horst, H.J.R. van der, Leppink, J., Koldewijn, E.L., Wagner, C. High level of patient satisfaction and comfort during diagnostic urological procedures performed by urologists and residents. Scandinavian Journal of Urełogy:7 2016, 50(3), 206-211

[8] de Vries AH, Boute MC, Kuppen MC, van Merrienboer JJ, Koldewijn EL, Pelger RC, et al. Patient safety risks of basic urological procedures performed by junior and senior residents. J Surg Educ 2015;72:918-26.

[9] Ericsson KA. Deliberate practice and acquisition of expert performance: a general overview. Acad Emerg Med 2008;15:988-94.

[10] Lee C, Woo HH. Current methods of analgesia for transrectal ultrasonography (TRUS)guided prostate biopsy - a systematic review. BJU Int 2014;113(Suppl 2):48-56.

[11] Tufek I, Akpinar H, Atug F, Obek C, Esen HE, Keskin MS, et al. The impact of local anesthetic volume and concentration on pain during prostate biopsy: a prospective randomized trial. J Endourol 2012;26: 174-7.

[12] Lynn NN, Collins GN, Brown SC, O'Reilly PH. Periprostatic nerve block gives better analgesia for prostatic biopsy. BJU Int 2002;90: 424-6.

[13] Patel AR, Jones JS, Babineau D. Lidocaine $2 \%$ gel versus plain lubricating gel for pain reduction during flexible cystoscopy: a metaanalysis of prospective, randomized, controlled trials. J Urol 2008;179:986-90.

[14] Ho KJ, Thompson TJ, O'Brien A, Young MR, McCleane G. Lignocaine gel: does it cause urethral pain rather than prevent it? Eur Urol 2003;43:194-6. 
Vries, A.H. de, Lesterhuis, E., Verweij, L.M., Schout, B.M.A., Horst, H.J.R. van der, Leppink, J., Koldewijn, E.L., Wagner, C. High level of patient satisfaction and comfort during diagnostic urological procedures performed by urologists and residents. Scandinavian Journal of Urełogy: 7 2016, 50(3), 206-211

nivel

TABLES

Table 1. Demographics.

\begin{tabular}{|c|c|c|c|c|c|c|c|}
\hline \multicolumn{4}{|c|}{ TRUSP } & \multicolumn{4}{|c|}{ UCS } \\
\hline Demographics & Urologist & Jr resident & Sr resident & Demographics & Urologist & $\mathrm{Jr}$ resident & Sr resident \\
\hline Total patients $(n=)$ & 39 & 31 & 14 & Total patients $(n=)$ & 44 & 75 & 19 \\
\hline Performed procedures $(k=)$ & $4(1-8)$ & $2(1-7)$ & $3(2-6)$ & Performed procedures $(k=)$ & $10(4-20)$ & $5(1-11)$ & $5(3-11)$ \\
\hline Gender (male) & $100 \%$ & $100 \%$ & $100 \%$ & Gender (male) & $68 \%$ & $61 \%$ & $32 \%$ \\
\hline Age (years) & $67(57-80)$ & $66(50-81)$ & $61(50-76)$ & Age (years) & $67(31-85)$ & $61(20-86)$ & $59(20-79)$ \\
\hline Indication & & & & Indication & & & \\
\hline Increased PSA & $56 \%$ & $77 \%$ & $79 \%$ & Haematuria & $11 \%$ & $16 \%$ & $32 \%$ \\
\hline LUTS & $0 \%$ & $3 \%$ & $7 \%$ & FU oncology & $59 \%$ & $40 \%$ & $11 \%$ \\
\hline Active surveillance & $31 \%$ & $20 \%$ & $14 \%$ & LUTS & $5 \%$ & $13 \%$ & $21 \%$ \\
\hline \multirow[t]{4}{*}{ Other } & $13 \%$ & $0 \%$ & $0 \%$ & Incontinence & $2 \%$ & $5 \%$ & $5 \%$ \\
\hline & & & & Recurrent UTI & $14 \%$ & $11 \%$ & $21 \%$ \\
\hline & & & & Other & $9 \%$ & $15 \%$ & $5 \%$ \\
\hline & & & & Missing & $0 \%$ & $0 \%$ & $5 \%$ \\
\hline Position & & & & Position & & & \\
\hline Dorsal lithotomy & $3 \%$ & $23 \%$ & $43 \%$ & Dorsal lithotomy & $55 \%$ & $97 \%$ & $100 \%$ \\
\hline Left lateral & $97 \%$ & $77 \%$ & $57 \%$ & Supine & $45 \%$ & $3 \%$ & $0 \%$ \\
\hline Periprostatic anaesthesia & & & & Cystoscope & & & \\
\hline Yes & $31 \%$ & $36 \%$ & $43 \%$ & Rigid & $0 \%$ & $12 \%$ & $16 \%$ \\
\hline No & $69 \%$ & $64 \%$ & $57 \%$ & Flexible & $100 \%$ & $88 \%$ & $84 \%$ \\
\hline \multirow[t]{3}{*}{ No. of biopsies } & $10(4-14)$ & $10(7-20)$ & $11(8-14)$ & Lubrication & & & \\
\hline & & & & Endosgel & $25 \%$ & $55 \%$ & $0 \%$ \\
\hline & & & & Instillagel & $75 \%$ & $45 \%$ & $100 \%$ \\
\hline $\begin{array}{l}\text { Previous TRUSP ( } n=\text { ) } \\
\text { Supervision }\end{array}$ & $1(0-4)$ & $0(0-3)$ & $0(0-4)$ & $\begin{array}{l}\text { Previous UCS }(n=) \\
\text { Supervision }\end{array}$ & $3(0-60)$ & $1(0-30)$ & $0(0-4)$ \\
\hline $\begin{array}{l}\text { Supervision } \\
\text { Yes }\end{array}$ & N/A & $16 \%$ & $0 \%$ & $\begin{array}{l}\text { Supervisi } \\
\text { Yes }\end{array}$ & N/A & $27 \%$ & $32 \%$ \\
\hline No & $\mathrm{N} / \mathrm{A}$ & $84 \%$ & $100 \%$ & No & N/A & $73 \%$ & $68 \%$ \\
\hline
\end{tabular}

Data are shown as $n$, median (min.-max.) or percentages.

"Performed procedures $(k=)$ " refers to the median number of procedures performed by the individual urologists and residents. "Previous TRUSP ( $n=$ )/UCS ( $n=)^{\text {") }}$ refers to the previous experience of patients in urethrocystoscopy (UCS) and transrectal ultrasound-guided prostate biopsy (TRUSP).

$\mathrm{Jr}=$ junior; $\mathrm{Sr}=$ senior; $\mathrm{PSA}=$ prostate-specific antigen; LUTS = lower urinary tract symptoms; $\mathrm{FU}=$ follow-up; UTI = urinary tract infection; N/A = not applicable.

Table 2. Outcomes of generalized estimating equations on patient experiences for urethrocystoscopy and transrectal ultrasound-guided prostate biopsy together.

\begin{tabular}{|c|c|c|c|c|c|c|c|c|c|}
\hline \multirow{2}{*}{ Model } & \multicolumn{3}{|c|}{ Patient satisfaction } & \multicolumn{3}{|c|}{ Pain experienced by the patient } & \multicolumn{3}{|c|}{ Patient comfort } \\
\hline & Wald $\chi^{2}$ & $\mathrm{df}$ & $p$ & Wald $\chi^{2}$ & $\mathrm{df}$ & $p$ & Wald $\chi^{2}$ & df & $p$ \\
\hline Previous experiences & 24.599 & 5 & $<0.001$ & 8.416 & 5 & 0.135 & 7.210 & 5 & 0.205 \\
\hline Procedure & 1.158 & 1 & 0.282 & 8.083 & 1 & 0.004 & 2.433 & 1 & 0.119 \\
\hline Group & 0.655 & 2 & 0.721 & 0.700 & 2 & 0.705 & 1.448 & 2 & 0.485 \\
\hline Procedure by Group & 3.785 & 2 & 0.151 & 0.353 & 2 & 0.838 & 0.030 & 2 & 0.985 \\
\hline Age & 20.534 & 1 & $<0.001$ & 6.385 & 1 & 0.012 & 12.960 & 1 & $<0.001$ \\
\hline Procedural time & 0.170 & 1 & 0.680 & 0.000 & 1 & 0.991 & 1.205 & 1 & 0.272 \\
\hline
\end{tabular}

In line with convention, $p$ values below $\alpha=0.05$ were considered statistically significant. 
Vries, A.H. de, Lesterhuis, E., Verweij, L.M., Schout, B.M.A., Horst, H.J.R. van der, Leppink, J., Koldewijn, E.L., Wagner, C. High level of patient satisfaction and comfort during diagnostic urological procedures performed by urologists and residents. Scandinavian Journal of Urełogy:7 2016, 50(3), 206-211

nivel

Table 3. Outcomes of generalized estimating equations on patient experiences for urethrocystoscopy for (a) men and (b) women.

\begin{tabular}{|c|c|c|c|c|c|c|c|c|c|}
\hline \multirow{2}{*}{ Model } & \multicolumn{3}{|c|}{ Patient satisfaction } & \multicolumn{3}{|c|}{ Pain experienced by the patient } & \multicolumn{3}{|c|}{ Patient comfort } \\
\hline & Wald $\chi^{2}$ & df & $p$ & Wald $\chi^{2}$ & df & $p$ & Wald $\chi^{2}$ & $\mathrm{df}$ & $p$ \\
\hline \multicolumn{10}{|l|}{ (a) Men } \\
\hline Previous experiences & 12.523 & 5 & 0.028 & 22.276 & 5 & $<0.001$ & 20.141 & 5 & 0.001 \\
\hline Position & 1.543 & 1 & 0.214 & 0.952 & 1 & 0.329 & 9.903 & 1 & 0.002 \\
\hline Lidocaine & 1.176 & 1 & 0.278 & 0.081 & 1 & 0.776 & 2.354 & 1 & 0.125 \\
\hline Age & 6.377 & 1 & 0.012 & 9.864 & 1 & 0.002 & 6.536 & 1 & 0.011 \\
\hline \multicolumn{10}{|l|}{ (b) Women } \\
\hline Previous experiences & 27.544 & 5 & $<0.001$ & 22.184 & 5 & $<0.001$ & 14.015 & 5 & 0.016 \\
\hline Type of scoop & 0.863 & 1 & 0.353 & 1.113 & 1 & 0.291 & 1.633 & 1 & 0.201 \\
\hline Position & 11.803 & 1 & 0.001 & 0.028 & 1 & 0.868 & 1.601 & 1 & 0.206 \\
\hline Lidocaine & 11.011 & 1 & 0.001 & 0.029 & 1 & 0.864 & 0.222 & 1 & 0.637 \\
\hline Age & 12.354 & 1 & $<0.001$ & 2.802 & 1 & 0.094 & 1.087 & 1 & 0.297 \\
\hline
\end{tabular}

In line with convention, $p$ values below $\alpha=0.05$ were considered statistically significant.

Table 4. Outcomes of generalized estimating equations on patient experiences for transrectal ultrasound-guided prostate biopsy specifically.

\begin{tabular}{|c|c|c|c|c|c|c|c|c|c|}
\hline \multirow[b]{2}{*}{ Model } & \multicolumn{3}{|c|}{ Patient satisfaction } & \multicolumn{3}{|c|}{ Pain experienced by the patient } & \multicolumn{3}{|c|}{ Patient comfort } \\
\hline & Wald $\chi^{2}$ & df & $p$ & Wald $\chi^{2}$ & df & $p$ & Wald $\chi^{2}$ & $\mathrm{df}$ & $p$ \\
\hline Previous experiences & 13.732 & 4 & 0.008 & 80.723 & 4 & $<0.001$ & 16.241 & 4 & 0.003 \\
\hline Position & 0.345 & 1 & 0.557 & 2.887 & 1 & 0.089 & 0.034 & 1 & 0.853 \\
\hline Lidocaine & 0.566 & 1 & 0.452 & 3.653 & 1 & 0.056 & 1.732 & 1 & 0.188 \\
\hline Age & 4.426 & 1 & 0.035 & 2.727 & 1 & 0.099 & 1.673 & 1 & 0.196 \\
\hline No. of biopsies & 0.043 & 1 & 0.835 & 0.722 & 1 & 0.396 & 0.611 & 1 & 0.434 \\
\hline
\end{tabular}

In line with convention, $p$ values below $\alpha=0.05$ were considered statistically significant. 